\title{
Etsiz Çiğ Köftelerde Patojen Candida spp. Varlığının Tespiti
}

\author{
Özen Kurşun Yurdakul', Seval Sevgi Kırdar ${ }^{2}$, Erhan Keyvan ${ }^{1}$ \\ ${ }^{1}$ Mehmet Akif Ersoy Universitesi, Veteriner Fakültesi, Besin Hijyeni ve Teknolojisi Anabilim Dall, Burdur \\ ${ }^{2}$ Mehmet Akif Ersoy Univ., Burdur Meslek Yüksekokulu, Gıda İsleme Böl., Süt ve Ürünleri Teknolojisi AD, Burdur
}

Geliş Tarihi / Received: 31.10.2016, Kabul Tarihi / Accepted: 14.04.2017

\begin{abstract}
Özet: Çiğ köfte, pişirilmeden tüketilen geleneksel hazır bir gıdadır. Artan tüketici taleplerinin karşılanabilmesi için endüstriyel üretimi yoğunluk kazanmış olan çiğ köfte, halk sağlığının korunması amacıyla çiğ et ilavesi olmadan üretilmektedir. Hammadde kalitesi, muhafaza koşulları, personel hijyeni ve ssıl işlem görmeden tüketilmesi gibi nedenler, çiğ köfteleri gıda hijyeni bakımından riskli hale getirmektedir. Bu çalışmada, 100 adet etsiz çiğ köfte örneği patojen Candida spp. varlığ1 yönünden analiz edildi. Etsiz çiğ köfte örneklerinin \%10'unda Candida albicans, \%2'sinde C. albicans ve C. krusei ile \%2'sinde ise C.albicans, C. tropicalis ve C. krusei olmak üzere üç farklı tür ile kontaminasyon tespit edildi. Gıda örneklerinin mikrobiyolojik incelemesinde toplam maya ve küf sayısı ile birlikte patojen mayaların varlığına yönelik analizlerin de yapılması toplum sağlığı açısından yararlı olacağı sonucuna varılmıştır.
\end{abstract}

Anahtar kelimeler: Etsiz çiğ köfte, Candida albicans, Candida tropicalis, Candida krusei.

\section{Detection of Pathogen Candida spp. in Cig Kofte-Meatless Raw Meatball}

\begin{abstract}
Cig köfte is a Turkish traditional ready to eat food and eaten without any cooking process. In order to maintain consumer demands, industrial production of cig köfte has become widespread in recent years, cig köfte is produced without the additon of raw meat for the protection of public health. Cig kofte is a potential problem for food hygiene because of such reasons like quality of raw material, storage conditions, personel hygiene and uncooked consumption. In this study, 100 meatless cig köfte samples were analyzed for occurrence of pathogen Candida spp. Candida albicans was detected 10\%,C. albicans and C. krusei were detected 2\% and C.albicans, C. tropicalis and C. krusei were detected $2 \%$ of meatless cig köfte samples. As a result of this studies, microbiological analysis of food samples should be detected for the presence of pathogenic yeast with total number of mold that it would be beneficial for public health.
\end{abstract}

Key words: Candida albicans, Candida tropicalis, Candida krusei, Candida, Meatless raw meatball.

\section{Giriş}

Çiğ köfte perakende satışı son yıllarda giderek yaygınlaşan geleneksel ürünlerimizden biridir. Geleneksel üretimde; yağsız sığır eti kıyması ile ince ögütülen bulgur içerisine çeşitli baharatlar, sarımsak, salça ve maydanoz eklenir. Bulgur yumuşayana kadar elle yoğrulur ve şekil verilerek tüketime hazır hale getirilir. Çiğ köftede çiğ et bulunması, ilave edilen malzemelerin hijyeni ile personel ve ekipmanlara bağlı nedenlerle mikroorganizma ve parazit kontaminasyonu şekillenebilir. Halk sağllğ 1 açısından potansiyel bir tehlike oluşturabileceğinden perakende satışlarda çiğ et kullanımı yasaklanmıştır. Etsiz hazırlanan çiğ köftelere 1sıl işlemi uygulanmadığı için baharat, alet ekipman ve hazırlayan kişiye bağlı olarak tüketimi bazı durumlarda riskli olabilir [10, 28, 29]. Özellikle baharat ve baharat katk1lı gida maddelerinde patojen mikroor- ganizmalardan kaynaklanan kontaminasyonlar her zaman mümkündür [12, 13 19].

Yeni antifungal ilaçların gelişmesi ile bu ilaçlara dirençli Candida türlerine bağlı enfeksiyonlarda önemli artışlar meydana gelmiştir. Hastane enfeksiyonu görülen yoğun bakım ünitelerinde bulunan mikroorganizmaların \%51'i gram negatif bakteri, $\% 35,2$ 'si gram pozitif bakteri, \%13,8'i Candida spp. olduğu görülmüştür [16]. Candida cinsi maya mantarları, Amerika Birleşik Devletleri (ABD) hastanelerinde kan dolaşımı enfeksiyonlarında \%8 ile dördüncü sırada görülen bir etkendir. İnvaziv kandidiyaz ile ilişkili mortalite önemlidir. Fransa'da yapılan toplum temelli yeni bir çalışmada, kandidemi ile ilişkili ölüm oranı $\% 40$ olarak bulunmuştur [4]. Hastane infeksiyonları patojenleri arasında dördüncü sıraya yükselen ve yüksek mortalite oranına sahip patojen Candida türleri aynı zamanda gıdalarla da insanlara bulaşmaktadır. Son yıllarda patojen

Yazışma adresi / Correspondence: Yrd. Doç. Dr. Erhan KEYVAN (ORCID: 0000-0002-2981-437X), Mehmet Akif Ersoy Üniversitesi Veteriner Fakültesi Besin Hijyeni ve Teknolojisi AD, Burdur,Türkiye E-posta: erhankeyvan@mehmetakif.edu.tr 
Candida spp. önemli bir gida patojeni olarak dikkatleri üstüne çekmektedir [25].

Candida türleri $6 \mu \mathrm{m}$ büyüklüğünde, Gram pozitif, oval, hareketsiz, kapsülsüz, sporsuz, tomurcuklanan hücreler olarak görülürler. Yalancı hif (psödohif) oluştururlar. Bunlar arasında C. albicans, blastokonidyum ve yalancı hif yanında gerçek hifler de oluşturarak dimorfik özellik gösterir [11,22].

Candida türleri, rutin besiyerleri olarak kullanilan Sabouraud-dekstroz-agar (SDA)' da, $24^{\circ} \mathrm{C}^{\prime} \mathrm{de}$ ve $37^{\circ} \mathrm{C}$ 'de 24 saatte üreyerek genellikle kirli-beyaz veya krem rengi, yumuşak kıvamlı ve tipik olarak mayams1, kokulu koloniler yaparlar. Kolonilerin besiyeri yüzeyinde kalan kısımları blastokonidyumlardan; besiyeri yüzeyinin altında ise yalancı hiflerden oluşmuştur. Candida türleri, besiyerlerinde saptanan blastokonidyumların özellikleri ile blastokonidyumların yalancı hif boyunca dizilimlerine göre farklar gösterir. Ayrıca türlerin kesin tanısı için şeker fermentasyonu ve biyokimyasal testler yapılır $[22,31]$.

C. albicans'1n diğer Candida türlerinden ayr1mında iki morfolojik test uygulanır. Serumda germ tüp oluşturması ve misır unlu Tween 80 agarda klamidospor oluşumu C. albicans'in karakteristik özelliğidir. C. tropicalis gerçek hif oluşturabilir, nadiren klamidospor oluşumu gözlenir, sukrozu asimile eder. C. krusei dekstrozu fermente eder ancak galaktozu asimile edemez [15].

Candida spp. türleri arasında en patojen tür $C$. albicans olup C. tropicalis ile C. krusei'ye bağlı enfeksiyonlarda da artış görülmektedir. C. albicans, hücre duvarında bulunan ve immünojen olan mannan tabakasının yapısal değişikliğine bağlı olarak A ve B olmak üzere iki serotipe ayrilır. C. albicans'ın mannan dişında diğer antijenleri; salgısal proteazlar, enolaz ve 1s1 şok proteinleridir [20].

Biyofilm oluşturma özelliğine sahip olmaları gıda sektörü açısından risk teşkil etmektedir. Biyofilm tabakada Staphylococcus spp. gibi bazı Candida türleri de slime benzeri yapılar oluşturmaktadır. Mikroorganizmalar bu slime tabakası içinde çoğalarak kalın bir film tabakasının şekillenmesine neden olur. Candida biyofilminin antifungal direnç gelişimine katkısının olduğu belirtilmektedir $[18,24]$.

Candida türleri normal floranın bir parçasıdır. İnsanların \%40-50'sinin gastrointestinal kanalında, geçici ya da kalıcı olarak bulunurlar. Ayrıca insanlarda ağız, deri, tırnak, kıl folliküllerine yerleşebilir [23]. Bunlara ilave olarak gida ve su ile alınarak hastalık meydana getirmektedir [5, 6, 30, 33]. Candida spp., vulvovaginitis, endokarditis, pnömoni, meningitis ve septisemi meydana getirebilir [23, 35].

$\mathrm{Bu}$ çalışmada, perakende satışı yapılan etsiz çiğ köftelerde patojen Candida spp. varlığının ortaya konulması ile gida kaynaklı muhtemel enfeksiyonlardaki rollerinin belirlenmesi amaçlanmıştır.

\section{Materyal ve Metot}

\section{Materyal}

$\mathrm{Bu}$ araştırmada, sadece çiğ köfte üretimi yapan işletmelerden 100 adet etsiz çiğ köfte örneği alınd1. Örnekler aseptik şartlar altında ve soğuk zincirde laboratuvara getirilerek analizleri yapıld 1 [14].

\section{Referans izolatlar}

Kontrol suşları olarak seçilen C. albicans (ATCC 97012), C. tropicalis (ATCC 13803), C. krusei (ATCC 14243) olmak üzere toplam 3 referans izolat kullanılmıştır.

\section{Besiyerleri}

Maya ve küf sayım1, pH'sı 3.5'e düşürülmüş Potato Dextrose Agar (PDA) (Difco B 13) besiyeri ile 22 \pm 1 ${ }^{\circ} \mathrm{C}$ 'de 5 gün inkübe edilerek yapıldı [14]. Patojen Candida spp. saptanmasi amaciyla CHROMAgar ${ }^{\mathrm{TM}}$ Candida agar (CAC) kullanılmıştır [25].

\section{Örneklerin analizi}

Sadece çiğ köfte üretimi yapılan işletmelerden toplam 100 adet etsiz çiğ köfte örneği toplanarak soğuk zincir altında laboratuvara getirildi. Her bir gida örneği aseptik koşullarda steril plastik torbalara 10'ar g tartılıp üzerine 90'ar ml steril peptonlu su (\%0.1) ilave edildikten sonra 2-3 dakika süre ile stomacher'da homojenize edildi. Elde edilen homojenize karışımdan $10^{-5}$ 'e kadar desimal sulandırmaları hazirlanarak PDA ve CAC besiyerine yayma plak tekniği ile ekimleri yapıldı $[3,21,27]$

Candida spp. şüpheli kolonilerden Gram boyama, germ tüp testi, karbonhidrat fermentasyon testleri (glikoz, maltoz, sukroz ve galaktoz) ile üreaz testleri gibi testler, biyokimyasal özelliklerin tespiti amaciyla yapıld 18,15$]$. 
Tablo 1. Patojen Candida spp.'nin CHROMagar Candida besiyerinde koloni görünümü ve türlerinin ayrımında kullanilan testler $[8,15,26]$.

\begin{tabular}{|c|c|c|c|c|c|c|c|c|}
\hline \multirow{2}{*}{ Tür ismi } & \multirow{2}{*}{$\begin{array}{c}\text { CHROMagar } \\
\text { koloni görünümü }\end{array}$} & \multirow{2}{*}{$\begin{array}{c}\text { Gram } \\
\text { boyama }\end{array}$} & \multirow{2}{*}{ Germ tüp } & \multirow{2}{*}{ Üreaz } & \multicolumn{4}{|c|}{ Karbonhidrat Fermentasyon Testleri } \\
\hline & & & & & Glikoz & Maltoz & Sukroz & Galaktoz \\
\hline C. albicans & Yeşil koloniler & $\operatorname{Gram}(+)$ & + & - & AG & AG & A & $\mathrm{AG}$ \\
\hline C. tropicalis & $\begin{array}{l}\text { Metalik mavi-koyu } \\
\text { mavi koloniler }\end{array}$ & $\operatorname{Gram}(+)$ & - & - & $\mathrm{AG}$ & $\mathrm{AG}$ & $\mathrm{AG}$ & $\mathrm{AG}$ \\
\hline C. krusei & Açık pembe koloniler & Gram $(+)$ & - & + & $\mathrm{AG}$ & - & - & - \\
\hline
\end{tabular}

$\mathbf{A}=$ asit oluşumu, $\mathbf{A G}=$ asit ve gaz oluşumu

\section{Bulgular}

Bu çalışmada, tüketime sunulan 100 adet etsiz çiğ köfte örneği patojen Candida spp. yönünden analize alındı. Etsiz çiğ köfte örneklerinin 10'unda (\%10) patojen Candida spp. saptand1. Pozitif örneklerin tamam1 (\%10) Candida albicans pozitif olarak tespit edildi. Candida spp. kontaminasyonu olan etsiz çiğ köfte örneklerinin 2'sinde (\%2) C. albicans ve $C$. krusei, 2'sinde de (\%2) C. albicans, C. tropicalis ve C. krusei olmak üzere diğer patojen türlerle kontaminasyon olduğu tespit edildi. Ayrıca analiz edilen 100 etsiz çiğ köfte örneğinde maya-küf sayılarının minimum $3.00 \log \mathrm{kob} / \mathrm{g}$ ile maksimum $7.34 \mathrm{log}$ ko$\mathrm{b} / \mathrm{g}$ arasinda olduğu, ortalama ise $4.934 \pm 0.093 \mathrm{log}$ kob/g düzeyinde olduğu saptand1.

\section{Tartışma ve Sonuç}

Çiğ köftede hijyen ve patojen mikroorganizma varlığ 1 yönünden yapılan birçok çalışma bulunmasına rağmen, yüksek mortalite oranına sahip patojen Candida spp. varlığının analizine yönelik herhangi bir çalışmanın olmadığ1 görülmüştür. Gıdalarda yapılan mikrobiyolojik analizlerde, toplam maya-küf sayısının uygun bulunması özellikle patojen Candida spp. içermediğini göstermemektedir. Toplam maya-küf sayısının yanında patojen mayaların da analizinin yapılması halk sağlığ meydana gelebilecek risklerin önlenmesi bakımından önemlidir.

Etsiz çiğ köfte örneklerinde 4,934 $\pm 0,093 \log$ $\mathrm{kob} / \mathrm{g}$ olarak bulduğumuz ortalama maya-küf değeri karşılaştırıldığında; Vural ve Yeşilmen [34] ile Cetin ve ark. [9] tarafindan bulunan değerden daha düşük, Cerit ve ark. [7] tarafından bulunan değerden yüksek, Sancak ve İşleyici [29], Aslan ve ark. [2] ve
Küplülü ve ark. [17] tarafından bulunan değerlere benzerlik gösterdiği saptanmıştır.

TSE K 144 Standardına [1] göre çiğ köftede maya-küf sayısı yönünden analiz edilen 5 örnekten 2 tanesinde bulunabilecek maksimum değer $10^{3}$ kob/g olarak belirtilmiştir. Analize alınan etsiz çiğ köfte örneklerinin \%99'u TSE K 144 Standardında verilen değerlerin üzerinde olduğu görülmüştür. Ticari olarak satışa sunulan etsiz çiğ köftelerin ilave katk1 maddesi ve bol miktarda baharat içermesi, açıta yoğurulması, üretimde kullanılan ekipman ve malzemelerin temizliği, satış yerinin hijyenik koşulları ve personel hijyeninin kötü olması gibi nedenlerle tüketimi riskli gıdalardan biri olduğu düşünülmektedir. Etsiz hazırlansa bile herhangi bir 1 sıl işleme tabi tutulmadan tüketime sunulması, gida zehirlenme olgularının görülmesine neden olabilir [9, 29]. Uzunlu [32] yaptığı çalışmada çiğ köftelerin içerisine katılan karabiberde 4,00 log kob/g, kuru soğanda $5.32 \log \mathrm{kob} / \mathrm{g}$ ve yeşil soğanda $4.11 \mathrm{log} \mathrm{kob} / \mathrm{g}$ maya-küf sayısı olduğunu tespit etmiştir. Baharatlarda ve katkı maddelerinde yüksek maya-küf sayısı üretim sonrası da mikrobiyal yükün yüksek olmasına neden olur. Diğer önemli bir risk ise tüketim sırasında organoleptik değişiklik gözlenmemesi tüketicinin ürünün tüketmesini engellememektedir.

Gida örneklerinin mikrobiyolojik incelemesinde toplam maya ve küf sayısını gösteren besiyerlerinin yanında patojen mayaların varlığının da incelenmesi toplum sağlı̆̆ bakımından önemli olduğu düşünülmektedir. İnsanlarda büyük sağlık problemleri oluşturan patojen Candida spp.'nin kontamine gıdalar ile de vücuda alınarak hastalık oluşturabilir. Mikrobiyolojik kriterlere uygun gidalarda bile patojen mayaların özellikle Candida spp.'ler bulunabilir. G1dalarda kromojenik besiyerinin patojen Candida 
spp.'lerin saptanmasında ve tür identifikasyonun da etkili olduğu, aynı zamanda kısa sürede sonuç verdiği görülmüştür.

Sonuç olarak; gün geçtikçe önemli sorunlar meydana getiren enfeksiyonlar içinde en sık görülen patojen Candida spp. türlerinin gidalarda da tanımlaması, protokoller ve tebliğlerin içerisinde bulunması halk sağlığı açısından faydalı olacaktır.

\section{Kaynaklar}

1. Anonim, (2012). Tüketime Hazır Etsiz Çiğ Köfte Standardı. TSE K 144. TSE, Ankara.

2. Arslan A, Güven A, Saltan S, Patır B, (1992). Elazığ'da tüketime sunulan çiğ köftelerin mikrobiyolojik kalitesi. FÜ Sağlık Bil Derg. 6, 13.

3. Bacteriological Analytical Manuel, (2001). Chapter 18 Yeasts, Molds and Mycotoxins.https://www.fda.gov/food/ foodscienceresearch/laboratorymethods/ucm071435.htm. Erişim tarihi: 14.04.2017

4. Bitar D, Lortholary O, Le Strat Y, Nicolau J, Coignard B, Tattevin P, Che D, Dromer F, (2014). Populationbased analysis of invasive fungal infections, France, 2001-2010. Emerg Infect Dis. 20, 1149-1155.

5. Buck JD, (1978). Comparison of an in situ and in vitro survival of Candida albicans in seawater. Microb Ecol. 4, 291302.

6. Buck JD, Bubucis PM, (1978). Filter procedure for enumeration of Candida albicans in natural waters. Appl Environ Microbiol. 35, 237-242.

7. Cerit İ, Deniz G, Yüleci T, Ergün BE, Aygün MG, Karaduman İ, Can C, Demirkol O, (2014). Sakarya İlinde Satışa Sunulan Etsiz Çiğ Köftelerin Fiziko-Kimyasal Özelliklerinin ve Monosodyum Glutamat İçeriğinin Belirlenmesi. Gıda Teknolojileri Elektronik Dergisi. 9(3), 10-17.

8. Cooper BH, Margarita SH, (1985). Yeast of medical importance. Balows A, Hausler WJ, Hermann KL, Isenberg HD, Shadomy HJ. eds. Manual of Clinical Microbiology. American Society for Microbiology, Washington, DC. p.526-41,

9. Çetin O, Bingöl EB, Akkaya H, (2008). The Microbiological, Serological and Parasitological Quality of Cig Kofte (Raw Meatball) and Its Lettuce Marketed in Istanbul. Polish J Environ Stud. 17, 701-706.

10. Delikanlı B, Sönmez B, Özdemir Y, (2014). Bursa Merkezinde Tüketime Sunulan Etsiz Çiğ Köftelerin Mikrobiyolojik Kalitesi. Harran Üniv Vet Fak Derg. 3(1), 13-17.

11. Dixon DM, Fromtling RA (1995). Morphology, taxonomy, and classifition of the fungi. Murray PR, Baron EJ, Pfaller MA. eds. Manual of Clinical Microbiology. 6th ed. Washington, DC. p.699-708.

12. Gieraltowski L, Julian E, Pringle J, Macdonald K, Quilliam D, Marsden-Haug N, (2013). Nationwide outbreak of Salmonella Montevideo infections associated with contaminated imported black and red pepper: warehouse mem- bership cards provide critical clues to identify the source. Epidemiol Infect. 141(6), 1244-52.

13. Hampikyan H, Bingol EB, Colak H, Aydin A, (2009). The evaluation of microbiological profile of some spices used in Turkish meat industry. J Food Agric Environ. 7(3/4), 111-15.

14. Koburger JA, Marth EH, (1984). Yeasts and Moulds. Speck ML. ed. Compendium of Methods for the Examination of Foods A.P.H.A. Washington D.C. p.197-202

15. Konemann WE, Allen SD, Janda MW, (1997). Color Atlas and Textbook of Diagnostic Microbiology. 5th ed. New York: Lippincott, p.983-1069.

16. Kölgelier S, Küçük A, Demir NA, Özçimen S, Demir LS, (2012). Yoğun Bakımlardaki Hastane Enfeksiyonları: Etiyoloji ve Predispozan Faktörler. Kafkas J Med Sci.2(1), $1-5$.

17. Küplülü Ö, Sarımehmetoglu B, Oral N, (2003). The microbiological quality of çiğ köfte sold in Ankara. Turk J Vet Anim Sci. 27, 325-329.

18. Mogha KV, Shah NP, Prajapati JB, Chaudhari AR, (2014). Biofilm - A threat to dairy industry. Indian J Dairy Sci. 67(6).

19. Moreira PL, Lourenção TB, Pinto JPAN, Rall VLM, (2009). Microbiological quality of spices marketed in the city of Botucatu, São Paulo, Brazil. J Food Prot. 72(2),421-424.

20. Morrison CJ, Hurst SF, Reis E, (2003). Competitive binding inhibition enzyme-linked immunosorbent assay that uses the secreted aspartyl proteinase of Candida albicans as antigenic marker for diagnosis of disseminated candidiasis. Clin Diagn Lab Immunol. 10, 835-848.

21. Mossela DAA, Kleynen-Semmeling MC, Vincenti HM, (1970). Oxytetracycline-Glucose-Yeast Extract Agar for Selective Enumeration of Moulds and Yeasts in Foods and Clinical Material. J Appl Bad. 33, 454-467.

22. Murray PR, Rosenthal KS, Pfaller MA, (2005). Fungal classification, structure, and replication. Murray PR, Rosenthal KS, Pfaller MA. eds. Medical microbiology, 5th edn. Mosby, Philadelphia, Pennsylvania. p.67-73

23. Odds FC, (1988). Candida and Candidosis. A review and bibliography. 2nd ed. London: BailliereTindall.

24. Pascual A, (2002). Pathogenesis of catheter-related infections:Lessons for new designs. Clin Microbiol Infect. 8, 256-264.

25. Pfaller MA, Diekema DJ, (2007). Epidemiology of invasive candidiasis: a persistent public health problem. Clin Microbiol Rev. 20, 133-163.

26. Pfaller MA, Houston A, Coffmann S, (1996). Application of CHROMagar Candida for rapid screening of clinical specimens for Candida albicans, Candida tropicalis, Candida krusei, and Candida (Torulopsis) glabrata . J Clin Microbiol. 34, 58-60.

27. Reisner BS, Woods GL, (1999). Specimen processing. Murray PR. eds. Manual of Clinical Microbiology 7.th edition, ASM Press Washington DC. p.64-104.

28. Sagun E, Sancak YC, Durmaz H, Akkaya L, (1997). A study on hygienic quality of raw meat balls consumed in Van. YYU Vet Fac J. 3, 64. 
29. Sancak YC, İşleyici Ö, (2006). Çiğ köftelerin mikrobiyolojik kalitesi üzerine bir araştırma. YYÜ Vet Fak Derg. 17, 81-86.

30. Spanamberg A, Ramos JP, Leoncini O, Alves SH, Valente P, (2009). High frequency of potentially pathogenic yeast species in goat's raw milk and creamed cheese in Southern Brazil. Acta Sci Vet. 37, 133-141.

31. Tümbay E, Seeliger HPR, Ang O, eds, (1991) Candida and Candidamycosis. New York: Plenum Press.

32. Uzunlu S, (2002). Çiğ Köftelerin Mikrobiyolojik Kalitesi ve Farklı Muhafaza Sicaklık ve Sürelerinde Mikrobiyal
Değişimin İncelenmesi. Yüksek Lisans Tezi, Akdeniz Ü Fen Bilimleri Enstitüsü, Antalya.

33. Valdes-Collazo L, Schultz AJ, Hazen TC, (1987) Survival of Candida albicans in tropical marine and fresh waters. Appl Environ Microbiol. 53(8), 1762-1767.

34. Vural A, Yeşilmen S, (2003). Diyarbakır'da satışa sunulan çiğ köftelerin mikrobiyolojik kalitesi üzerine bir araştırma. Türk Mikrobiyol Cem Derg. 33, 350-355.

35. Warren NG, Haznen KC, (1999). Candida, Cryptococcus, and other yeasts of medical importance. Murray PR. eds. Manual of Clinical Microbiology 7.th edition, ASM Press, Washington DC. p.1184-1199. 